\title{
TCCS
}

\section{PRODUTO FACILITADOR DA SEPARAÇÃO DE RESÍDUO DOMÉSTICO}

\author{
Rafaela Sordi Lopes da Silva, Bacharel (UFSC); \\ Orientador - Ana Veronica Pazmino, Dra. (UFSC)
}

\section{INTRODUÇÃO}

Atualmente um tema muito recorrente em todas as áreas de estudo é a sustentabilidade e os problemas relacionados ao meio ambiente. No campo do design muito se ouve falar sobre eco design, design e sustentabilidade, produtos sustentáveis e como o design pode desempenhar um papel importante para minimizar as problemáticas ambientais.

Leonard (2011) menciona que diversos estudos apontam o crescimento populacional como uma das grandes razões para o aumento do consumo e consequentemente a problemática do aumento de resíduos sólidos. Segundo a autora ao longo do século XX, a quantidade de lixo aumentou mais de dez vezes, passando de $42 \mathrm{~kg}$ a $563 \mathrm{~kg}$ por pessoa ao ano, o que equivale a 1,54 $\mathrm{kg}$ por pessoa ao dia.

O reuso e a reciclagem são apontadas como soluções para reduzir o acúmulo de lixo e como formas de destino adequado para os resíduos produzidos.

Para contribuir com o destino adequado de resíduos, o projeto de conclusão de curso visou desenvolver um produto para possibilitar a separação do resíduo sólido doméstico visando incentivar e facilitar o posterior reuso e a reciclagem. Os objetivos que nortearam o projeto foram:

1.Levantar informações sobre resíduo sólido doméstico e coleta seletiva;

2.Descreveroeco designedesigne sustentabilidade;

3.Apresentar princípios de design de produto, materiais sustentáveis, reuso e reciclagem;

4.Definir o Público alvo;

5. Analisar produtos similares;

6. Estabelecer requisitos de projeto;

7 Gerar alternativas e analisar as alternativas obtidas;

8. Desenvolver e construir modelo funcional.

\section{DESENVOLVIMENTO}

Para o desenvolvimento do projeto foi seguido o processo projetual de Gui Bonsiepe (1984) que apresenta 5 fases: Problematização ou Formulação; Análise; Definição do problema, Anteprojeto o Projeto.

Na fase de Problematização ou Formulação foi estudado o contexto da problemática relacionada ao tema do projeto. Alguns dos assuntos tratados foram: informações sobre resíduo sólido doméstico e coleta seletiva; eco design e design e sustentabilidade; princípios de design de produto; materiais sustentáveis; reuso e reciclagem. Na fase de análise foi definido o público alvo, aplicados questionários e entrevista com o Gerente do Departamento de Coleta de Resíduos Sólidos, Paulo Roberto da Rocha e Pinho, da Companhia Melhoramentos da Capital de Florianópolis (Comcap). Foram analisados produtos concorrentes e similares.

Na fase de definição do problema foram montados infográficos, personas, quadro de requisitos de projeto. Utilizando os métodos mostrados em Pazmino (2015). Na fase de anteprojeto foram geradas alternativas e posteriormente seguidas da avaliação da solução. Finalmente na fase de projeto foi feita a construção do modelo funcional em tamanho real. A figura 1 mostra o rendering do produto SEPARA. 
Figura 1 Rendering SEPARA

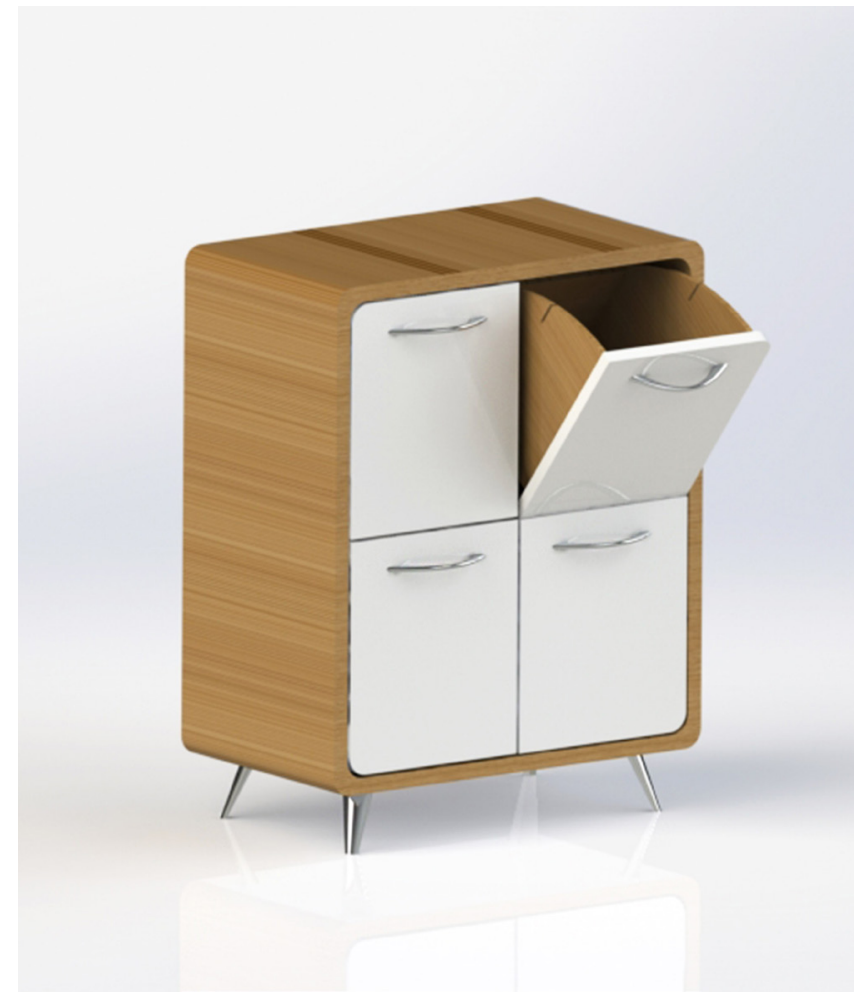

Fonte: Da Silva (2015

\section{REFERÊNCIAS}

1. BONSIEPE, Gui et al. Metodologia experimental: desenho industrial. Brasília: CNPq / 1984.

2. DA SILVA. Rafaela. Produto facilitador da separação de resíduo doméstico. PCC. UFSC. Florianópolis. 2015.

3. LEONARD, Annie; CONRAD, Ariane. A História das Coisas: Da natureza ao lixo, o que acontece com tudo que consumimos. Rio de Janeiro: Zahar, 2011.

4. PAZMINO, Ana Veronica. Como se cria: 40 métodos para o design de produtos. São Paulo: Ed. Blucher. 2015. 